\title{
Heterobimetallic Complexes as Catalyst Precursors for the Oppenauer-Type Oxidation of Alcohols
}

\author{
Sébastien Gauthier§ and Kay Severin* \\ §SCS Poster Prize Winner
}

\begin{abstract}
A heterobimetallic $\mathrm{Ru}(I)-\mathrm{Rh}(\mathrm{I})$ complex has been identified as a potent catalyst precursor for the $\mathrm{Op}$ penauer-type oxidation of alcohols. With $0.1-0.5 \mathrm{~mol} \%$ of this complex and $\mathrm{K}_{2} \mathrm{CO}_{3}$ as the co-catalyst, it is possible to oxidize secondary and primary alcohols at ambient temperature using acetone as the solvent and oxidation agent.
\end{abstract}

Keywords: Alcohol · Catalysis · Oxidation · Rhodium $\cdot$ Ruthenium

Alcohols can be oxidized in hydrogen transfer reactions using ketones such as acetone as the solvent and oxidation agent. This type of reaction is very appealing, both from an environmental as well as economical point of view. Several transition metal complexes have been reported to catalyze this reaction. With the simple triphenylphosphine complex $\left[\mathrm{RuCl}_{2}\left(\mathrm{PPh}_{3}\right)_{3}\right]$ and $\mathrm{K}_{2} \mathrm{CO}_{3}$ as the co-catalyst, for example, it is possible to oxidize secondary alcohols with turnover numbers exceeding 500 using acetone as the oxidation agent [1][2]. Most of the ruthenium-based catalysts described so far, however, require elevated temperatures and do not work with primary alcohols as substrates.

Over the last years, we have been interested in the synthesis and the catalytic properties of bimetallic complexes, in which two different metal fragments are

${ }^{*}$ Correspondence: Prof. K. Severin

Institut des Sciences et Ingénierie Chimiques

Ecole Polytechnique Fédérale de Lausanne (EPFL)

$\mathrm{CH}-1115$ Lausanne

Tel.: +41216939302

Fax: + 41216939305

E-Mail: kay.severin@epfl.ch

http://isic.epfl.ch/severin fe.htm connected by either two or three halogeno bridges [3-9]. During the course of this work we discovered that heterometallic $\mathrm{Ru}(\mathrm{II})-\mathrm{Rh}$ (I) complexes containing a cyclopentadienone-rhodium fragment can be obtained in chloro bridge metathesis reactions of complex $\mathbf{1}$ or $\mathbf{2}$ with various dinuclear ruthenium complexes [10-12]. Some representative examples are shown in Scheme 1. Complex 6 turned out to be a very potent catalyst precursor for atom transfer radical additions of $\mathrm{CCl}_{4}$ to olefins [10]. With complex 9, on the other hand, it is possible to catalyze the Oppenauer-type oxidation of primary and secondary alcohols under very mild conditions as summarized below. A more comprehensive discussion of these hydrogen transfer reactions can be found in a recent publication [12].

Complex 9 was identified as a highly efficient catalyst in a small screening using the oxidation of 1-phenylethanol as the benchmark reaction (Scheme 2). With $0.2 \mathrm{~mol} \%$ of the complex and equimolar amounts of $\mathrm{K}_{2} \mathrm{CO}_{3}$ (with respect to the substrate), the oxidation to acetophenone proceeded with a conversion of $70 \%$ in $6 \mathrm{~h}$ at room temperature. Control experiments with the pure

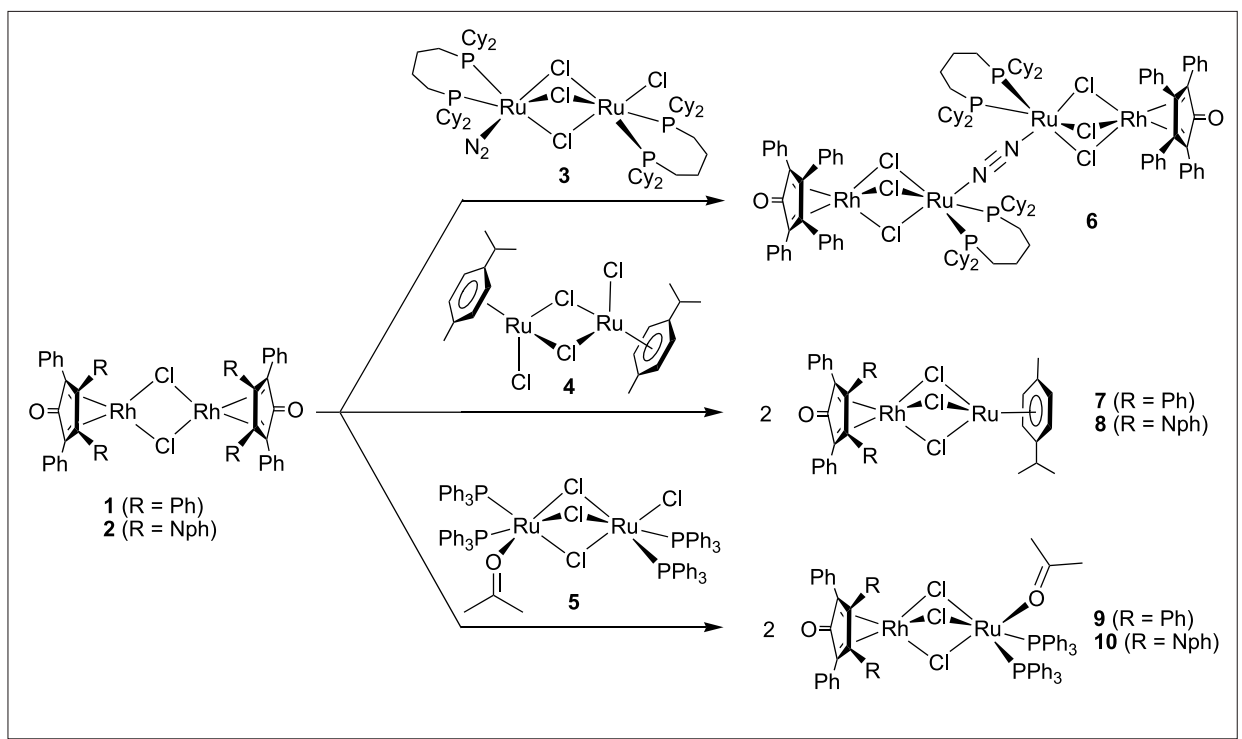

Scheme 1. Synthesis of heterometallic $\mathrm{Ru}(\mathrm{II})-\mathrm{Rh}(\mathrm{I})$ complexes by chloro bridge metathesis 
homodimeric complexes $\mathbf{1}$ and $\mathbf{5}$ gave only very low conversions $(\leq 1 \%)$. A comparison of the results obtained for complex $\mathbf{1 0}$ (conversion: $30 \%$ ) showed that the introduction of a sterically demanding naphthyl group on the cyclopentadienone ligand is detrimental for catalytic activity. To put the results with the new catalyst 9 into perspective, we have also investigated the benchmark reaction with $\left[\mathrm{RuCl}_{2}\left(\mathrm{PPh}_{3}\right)_{3}\right]$. Although this complex is a good catalyst at elevated temperatures, it gives a very poor conversion at room temperature $(2 \%)$.

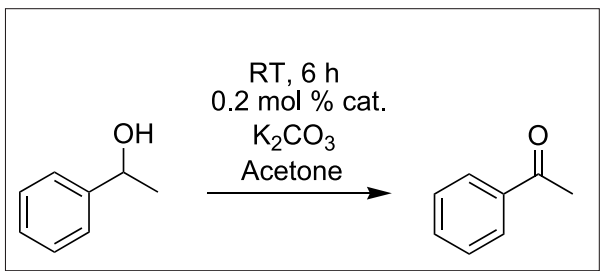

Scheme 2. Catalytic oxidation of 1-phenylethanol to acetophenone as the benchmark reaction

The scope of the new heterobimetallic $\mathrm{Rh}(\mathrm{I})-\mathrm{Ru}(\mathrm{II})$ catalyst precursor 9 was investigated in reactions with a number of secondary and primary alcohols. With $0.1-0.5 \mathrm{~mol} \%$ of this complex, aromatic and aliphatic secondary alcohols were oxidized at room temperature to the corresponding aldehydes and ketones with good to excellent conversions (Table). Stoichiometric amounts of $\mathrm{K}_{2} \mathrm{CO}_{3}$ were employed since reactions with catalytic amounts of $\mathrm{K}_{2} \mathrm{CO}_{3}(10 \mathrm{~mol} \%)$ gave slightly lower conversions. Primary alcohols required higher catalyst loadings but typical side products such as aldol condensation products or the Tishchenko reaction products could not be observed by gas chromatography. Aliphatic primary alcohols such as 1-octanol, however, gave only low conversions as a result of their unfavorable redox potential with respect to the acetone/2-propanol pair.

The new catalyst 9 was also analyzed by single crystal $\mathrm{X}$-ray analysis. As anticipated, a $\mathrm{RuCl}_{2}\left(\mathrm{PPh}_{3}\right)_{2}$ fragment is connected via three chloro-bridges to a $\left(\eta^{4}-\mathrm{C}_{4} \mathrm{Ph}_{4} \mathrm{CO}\right) \mathrm{RhCl}$ fragment (Fig.). The remaining coordination site at the ruthenium complex is occupied by an acetone ligand. The resulting octahedral $\mathrm{Ru}$ center is slightly distorted as a result of the two sterically demanding phosphine ligands. The rhodium exhibits a five-coordinated, electronically saturated configuration.

It is plausible that the reactions take place at the electronically unsaturated ruthenium center, which is generated after liberation of the labile acetone ligand. The base $\mathrm{K}_{2} \mathrm{CO}_{3}$ is expected to facilitate the formation of a metal-alkoxide complex, which could then undergo $\beta$-hydride elimination to give a hydride complex. The $\left(\eta^{4}-\mathrm{C}_{4} \mathrm{Ph}_{4} \mathrm{CO}\right) \mathrm{Rh}$ fragment could also participate in catalysis since
Table. Oxidation of primary and secondary alcohols catalyzed by complex 9. The reactions were performed at room temperature in the presence of $\mathrm{K}_{2} \mathrm{CO}_{3}$ (1 equiv.) with acetone as the solvent and oxidation agent.

$\begin{array}{llll}\text { substrate } & \text { catalyst/substrate [mol\%] } & \text { time [h] } & \text { conv. [\%] } \\ \text { 1-phenylethanol } & 0.5 & 6 & 94 \\ \text { 1-phenylethanol } & 0.1 & 24 & 78 \\ \text { 1-indanol } & 0.1 & 24 & 96 \\ \text { benzhydrol } & 0.5 & 24 & 97 \\ \text { cycloheptanol } & 0.5 & 24 & >99 \\ \text { 2-octanol } & 0.5 & 24 & 77 \\ \text { benzyl alcohol } & 0.5 & 24 & 54 \\ \text { 4-methoxybenzyl alcohol } & 0.5 & 24 & 90 \\ \text { 1-octanol } & 0.5 & 24 & 10\end{array}$

it has been described for $\left(\eta^{4}-\mathrm{C}_{4} \mathrm{Ph}_{4} \mathrm{CO}\right) \mathrm{Ru}$ complexes that the carbonyl group of the $\beta$ ligand is able to accept hydrogen [13][14]. Attempts to identify intermediates of the catalytic cycle by NMR spectroscopy were so far not successful. It is important to point out, however, that both the rhodium- as well as the ruthenium fragment are essential for the high activity of the new catalyst as evidenced by control experiments.

Overall, these results are another demonstration for the potential of mixed halogeno-bridged complexes in homogeneous catalysis. Heterobimetallic complexes such as 9 can be easily generated from common starting materials. This facilitates the fast screening of a structurally diverse set of complexes [10]. Reactions with strong donor ligands such as $\mathrm{CO}$ should be avoided for this class of catalysts, however, because cleavage of the halogeno bridge is expected. Despite this limitation, we believe that heterobimetallic, halogeno-bridged complexes will increasingly be used for transition metal catalyzed reactions.

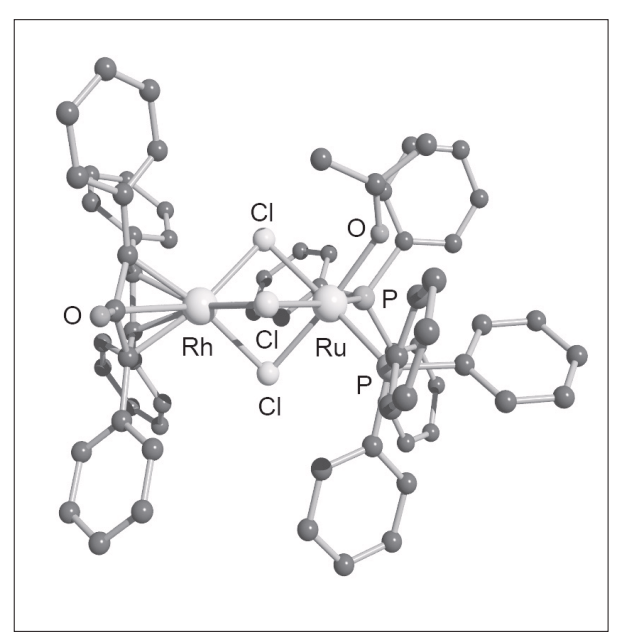

\section{Acknowledgements}

This work was supported by the Swiss National Science Foundation. We thank R. Scopelliti who performed the crystal X-ray analyses described in this overview.

Received: December 13, 2004

[1] M.L.S. Almeida, M. Beller, G.-Z. Wang, J.-E. Bäckvall, Chem. Eur. J. 1996, 2, 1533-1536.

[2] J.-E. Bäckvall, J. Organomet. Chem. 2002, 652, 105-111.

[3] L. Quebatte, M. Haas, E. Solari, R. Scopelliti, Q.T. Nguyen, K. Severin, Angew. Chem. Int. Ed. 2005, 44, 1084-1088.

[4] S. Gauthier, L. Quebatte, R. Scopelliti, K. Severin, Inorg. Chem. Commun. 2004, 7, 708-712.

[5] S. Gauthier, L. Quebatte, R. Scopelliti, K. Severin, Chem. Eur. J. 2004, 10, 28112821.

[6] K. Severin, Chem. Eur. J. 2002, 8, 15141518.

[7] A.C. da Silva, H. Piotrowski, P. Mayer, K. Polborn, K. Severin, Eur. J. Inorg. Chem. 2001, 685-691.

[8] M. Öhm, A. Schulz, K. Severin, Eur. J. Inorg. Chem. 2000, 2623-2629.

[9] A.C. da Silva, H. Piotrowski, P. Mayer, K. Polborn, K. Severin, J. Chem. Soc., Dalton Trans. 2000, 2960-2963.

[10] L. Quebatte, R. Scopelliti, K. Severin, Angew. Chem. Int. Ed. 2004, 43, 1520 1524.

[11] S. Gauthier, R. Scopelliti, K. Severin, Helv. Chim. Acta 2005, in press.

[12] S. Gauthier, R. Scopelliti, K. Severin, Organometallics 2004, 23, 3769-3771.

[13] H.M. Jung, J.H. Choi, S.O. Lee, Y.H. Kim, J.H. Park, J. Park, Organometallics 2002 , 21, 5674-5677.

[14] G. Csjernyik, A.H. Éll, L. Fadini, B. Pugin, J.-E. Bäckvall, J. Org. Chem. 2002, 67, 1657-1662.
Fig. Ball and stick representation of the molecular structure of $\mathbf{9}$ in the crystal. The hydrogen atoms are omitted for clarity. 